\title{
A Typical Case of Posterior Reversible Encephalopathy Syndrome Associated with Postpartum Eclampsia-HELLP Syndrome
}

\author{
Hiroshi Takagi, Kazutoshi Matsunami, Satoshi Ichigo, Takuma Katano, Atsushi Imai* \\ Department of Obstetrics and Gynecology, Matsunami General Hospital, Kasamatsu, Japan \\ Email: *aimai@matsunami-hsp.or.jp
}

Received 29 March 2016; accepted 7 May 2016; published 10 May 2016

Copyright (C) 2016 by authors and Scientific Research Publishing Inc.

This work is licensed under the Creative Commons Attribution International License (CC BY). http://creativecommons.org/licenses/by/4.0/

(c) (i) Open Access

\begin{abstract}
Background: Posterior reversible encephalopathy syndrome (PRES) is a reversible syndrome characterized by seizures, headache, altered mentation, and loss of vision associated with white matter changes on imaging. Case: A 37-year-old multigravida woman had a severe, immediate postpartum eclampsia-HELLP syndrome (hemolysis, elevated liver enzyme levels, low platelet count) with PRES characterized by generalized seizures and altered mental status. Magnetic resonance brain imaging showed high-intensity lesions in non-posterior portions including the frontal lobe and cingulated gyrus, which resolved completely after 2 weeks along with complete symptom regression. Conclusions: Cases of postpartum PRES without involvement of posterior brain regions after eclampsia-HELLP syndrome are very rare. Patients with PRES do not always show typical manifestations. The importance of a prompt diagnosis is emphasized, as is the crucial role of rapid blood pressure reduction.
\end{abstract}

\section{Keywords}

Posterior Reversible Encephalopathy Syndrome, Eclampsia, HELLP Syndrome, Non-Posterior Lobes

\section{Introduction}

Posterior reversible encephalopathy syndrome (PRES) has a unique neuroradiological finding of vasogenic edema in the brain and clinical symptoms including headache, altered mental function, seizure, and visual disturbance [1]-[4]. Edema is predominant in the posterior portions of the white matter. Recent studies have also

\footnotetext{
${ }^{*}$ Corresponding author.
}

How to cite this paper: Takagi, H., Matsunami, K., Ichigo, S., Katano, T. and Imai, A. (2016) A Typical Case of Posterior Reversible Encephalopathy Syndrome Associated with Postpartum Eclampsia-HELLP Syndrome. Open Journal of Obstetrics and Gynecology, 6, 355-359. http://dx.doi.org/10.4236/ojog.2016.66045 
documented prevalent extension of edema into the brainstem and basal ganglia [5]-[8]. Hypertensive encephalopathy is the well-known cause, and renal decompensation, fluid retention, and the use of immunosuppressive drugs are other common etiologies. For pregnant and immediate postpartum women, (pre-)eclampsia is an important cause of PRES [9]-[12]. HELLP syndrome (hemolysis, elevated liver enzyme levels, low platelet count) is a pregnancy-related disorder that is regarded as being a variant of eclampsia. It is thought to be due to microvascular injury with diffuse endothelial damage caused by hypertention or by an immunopathological mechanism. Only isolated reports of PRES associated with HELLP syndrome have been published so far [13]-[16]. We describe an atypical case of PRES involving non-posterior portions (the frontal lobe and cingulated gyrus) immediate postpartum eclampsia-HELLP syndrome.

\section{Case Presentation}

A 37-year-old woman, G1P1, without a family history of hypertention or epilepsy, was seen at gestation of 38 weeks and 5 days for normal delivery. Her antenatal care was uneventful. Her blood pressure at admission was 178/98 mmHg and she was started on oral antihypertensives (calcium channel blocker). One hour after admission, a 2854 g baby was born with spontaneous vaginal delivery; Apgar scores of 10 at 5 min. Blood pressure was controlled with continuous intravenous infusion of antihypertensives (calcium channel blocker).

Two hours after delivery she developed sudden onset of epigastralgia, vomiting and giddiness. Blood chemistry showed hypertransaminasemia, thrombocytopenia, microangiopathic hemolytic anemia, schistocytes, increased lactate dehydrogenase levels (2253 IU), and haptoglobin < $5.0 \mathrm{mg} / \mathrm{dl}$ (normal range 61 - 200); serum bilirubin was $2.2 \mathrm{mg} / \mathrm{dl}$ (normal range 0 - 1). Antithrombin III and fibrin/fibrinogen degradation products were $67 \%$ (normal range 79 - 121) and $22.0 \mu \mathrm{g} / \mathrm{ml}$ (normal range < 4.0), respectively. Glucose, creatinine, and serum electrolytes were normal. A diagnosis of postpartum HELLP syndrome was established. The patient was commenced on magnesium sulfate and nafamostat mesilate infusion, and intermittent infusion of hydralazine and human antithrombin III concentrates.

Fifteen hours after delivery, the patient developed a generalized tonic-clonic seizure which was spontaneously controlled within 10 min without diazepam. No neurological focal deficit at that time of clinical assessment was found. A cranial computed tomography (CT) showed discreet hypodensity on the right and left frontal lobes (Figure 1). There was no evidence of intracranial hemorrhage, cerebral infarction, or cerebral venous sinus thrombosis. An urgent brain magnetic resonance imaging (MRI) showed high-intensity lesions in the superior frontal gyrus, the precentral gyrus and the cingulate gyrus (Figure 2). These images ruled out the possibility of cerebral venous sinus thrombosis and cortical blindness. Elevated blood pressure persisted, requiring intravenous infusion of nicardipine. An intravenous infusion of magnesium sulfate was also continued. At 48 hours, the intravenous infusion was suspended and oral treatment was initiated with amlodipine $5 \mathrm{mg} /$ day and telmisartan $20 \mathrm{mg} /$ day. The blood pressure had gradually improved and the MRI on postpartum day 12 showed that all lesions disappeared (Figure 3), and a diagnosis of PRES. The patient was discharged, using oral antihypertensives (calcium channel blocker).

\section{Discussion}

This report describes a case of HELLP syndrome occurring in the immediate postpartum period that was asso-


Figure 1. Cranial CT indicating discreet hypodensity in the left (a) and right (b) frontal lobes. 



Figure 2. MRI, T2-weighted axial images indicating high signal lesions in cingulate gyrus (a), and the right frontal lobe (b), (c).
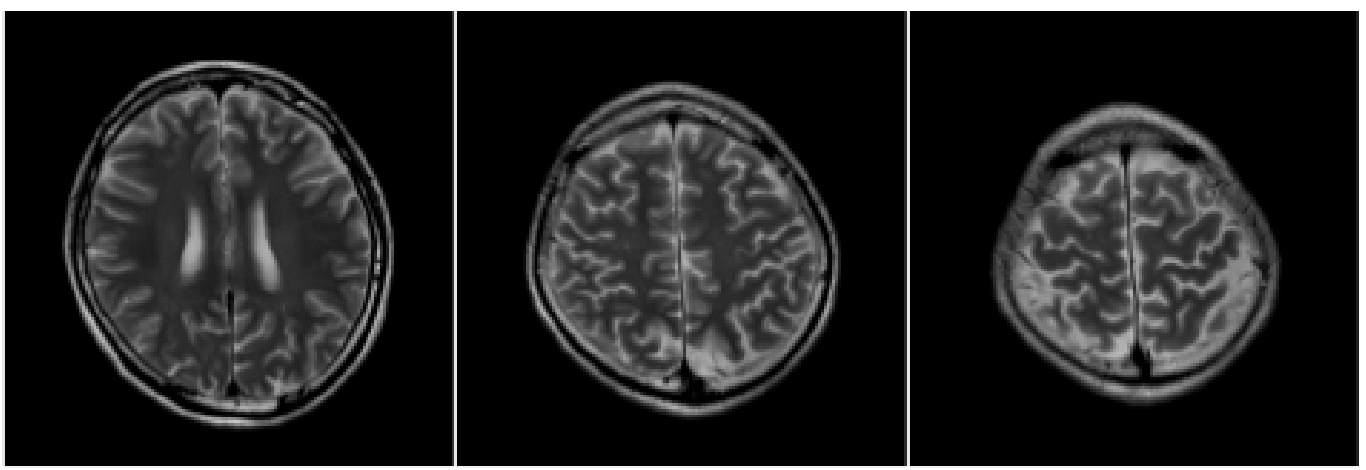

Figure 3. Follow-up MRI indicating that all lesions have disappeared.

ciated with clinical and neuroradiological findings consistent with PRES. HELLP syndrome represents a complication of pre-eclampsia. It can occur at any time during pregnancy, but rarely before 20 weeks; about onethird of cases of HELLP syndrome occur postpartum [14] [17]. Not all women with HELLP syndrome develop hypertension. Headache, nausea and vomiting, seizures, and altered consciousness represent frequent clinical findings. Focal or lateralizing neurologic signs also occur. PRES has usually been described in association with hypertensive encephalopathy, eclampsia, renal failure, of following immunosuppressive or cytotoxic therapy. PRES may occur with a mild elevation in blood pressure and even in normotensive patients [9] [11] [12] [14] [15] [18]. It is believed that a rapid rise in blood pressure overcomes cerebral autoregulatory mechanisms with abrupt dilatation of cerebral arterioles. The most characteristic imaging pattern in PRES is the presence of edema involving the white matter of the posterior portion of both cerebral hemispheres, especially the parietooccipital regions, in a relatively symmetric pattern that spares the calcarine and para-median parts of the occipital lobes [1] [6] [9] [15]. Asymmetric appearance had also been noted [8]. Other structures such as the brain stem, cerebellum, and frontal and temporal lobes may also involved, and although the abnormality primarily affects the sub-cortical white matter, the cortex and the basal ganglia my also be involved [5]-[7], as in the case reported herein. Pen et al. [13] showed a case of postpartum RPLS without involvement of posterior brain regions after eclampsia complicated by HELLP syndrome. A 36-year-old primigravid woman underwent induction of labor due to mild pregnancy-induced hypertension. At $5 \mathrm{~h}$ after delivery, she developed eclampsia seizures complicated by HELLP syndrome. MRI showed high intensity lesions in anterior regions without any abnormalities in posterior cerebral regions.

Whilst the reversibility of vasogenic edema is typical, early damage may also cause ischemia [9] [11] [12] [15] [18]. Neuroradiographic abnormalities of PRES are often apparent on CT scans, as in the case reported herein [1] [17] [19]. MRI plays an important role in providing early information about cerebral involvement, revealing signal abnormalities involving the subcortical white matter. Differential diagnosis of PRES in pregnancy and puerperium may be difficult; it includes stroke, cerebral venous thrombosis, encephalitis, and metabolic and demyelinating disorders [4] [17]. The appropriate and rapid lowering of blood pressure in patients with PRES is 
essential to avoid permanent brain injury. The clinical and neuroimaging findings tend to be reversible once the underlying cause of PRES is identified and treated.

Aggressive antihypertensive treatment should be commenced in all women with a systolic blood pressure $\geq 170 \mathrm{mmHg}$ or a diastolic blood pressure $\geq 110 \mathrm{mmHg}$ because of the risk of intracerebral hemorrhage and eclampsia [19] [20]. While there is no controlled trial to determine how long severe hypertension may be left untreated, it is recommended that treatment be administered promptly, aiming for a gradual and sustained lowering of blood pressure. Drugs for the treatment of very high blood pressure in pregnancy have been the subject of a Cochrane review, which concluded that no good evidence exists to prove that any short-acting antihypertensive is better than another [19] [21] [22]. The agent of choice for the acute treatment of hypertension is oral nifedipine. Headache is a frequent side-effect. Intravenous labetolol is the agent of choice for intravenous administration. The third agent of choice is hydralazine. Magnesium sulfate therapy is recommended for use antepartum and intrapartum and within the first $24 \mathrm{~h}$ postpartum for severe preeclampsia when the following factors are present: 1) persistently elevated blood pressure despite adequate hypotensive therapy and appropriate fluid management and 2) evidence of central nervous system dysfunction, thrombocytopenia or liver disease [19] [21] [22].

\section{Conclusion}

In summary, PRES is an interesting yet confusing finding associated with HELLP syndrome and eclampsia. It should be kept in mind as a differential diagnosis in postpartum women presenting with seizures, headache, altered mentation, and loss of vision. Cases of postpartum PRES without involvement of posterior brain regions after eclampsia-HELLP syndrome are very rare. However, patients with PRES do not always show typical manifestations. The importance of a prompt diagnosis is emphasized, as is the crucial role of rapid blood pressure reduction.

\section{Conflict of Interest}

There is no conflict of interests regarding the publication of this paper.

\section{References}

[1] Ducros, A., Boukobza, M., Porcher, R., Sarov, M., Valade, D. and Bousser, M. (2007) The Clinical and Radiological Spectrum of Reversible Cerebral Vasoconstriction Syndrome. A Prospective Series of 67 Patients. Brain, 130, 30913101. http://dx.doi.org/10.1093/brain/awm256

[2] Sraykov, D. and Schwab, S. (2012) Posterior Reversible Encephalopathy Syndrome. Journal of Intensive Care Medicine, 27, 11-24. http://dx.doi.org/10.1177/0885066610393634

[3] Lee, V., Wijdicks, E., Manno, E. and Rabinstein, A. (2008) Clinical Spectrum of Reversible Posterior Leukoencaphalopathy Syndrome. Archives of Neurology, 65, 205-210.

[4] Garg, R. (2001) Posterior Leukoencephalopathy Syndrome. Postgraduate Medical Journal, 77, 24. http://dx.doi.org/10.1136/pmj.77.903.24

[5] Covarrubias, D., Luetmer, P. and Campeau, N. (2002) Posterior Reversible Encephalopathy Syndrome: Prognostic Utility of Quantitative Diffusion-Weighted MR Images. American Journal of Neuroradiology, 23, 1038-1048.

[6] Lee, H. (2007) Posterior Reversible Encephalopathy Syndrome. Applied Radiology, 36, 42-43.

[7] McKinney, A., Short, J., Truwit, C., McKinney, Z., Kozak, O., Santa Cruz, K. and Teksam, M. (2007) Posterior Reversible Encephalopathy Syndrome: Incidence of Atypical Regions of Involvement and Imaging Findings. American Journal of Roentgenology, 189, 904-912. http://dx.doi.org/10.2214/AJR.07.2024

[8] Mirza, A. (2006) Posterior Reversible Encephalopathy Syndrome: A Variant of Hypertensive Encephalopathy. Journal of Clinical Neuroscience, 13, 595-598. http://dx.doi.org/10.1016/j.jocn.2005.03.042

[9] Brewer, J., Owens, M., Wallace, K., Reeves, A., Morris, R., Khan, M., LaMarca, B. and Martin, J.J. (2013) Posterior Reversible Encephalopathy Syndrome in 46 of 47 Patients with Eclampsia. American Journal of Obstetrics and Gynecology, 468, e1-e6.

[10] Uwatoko, T., Toyoda, K., Hirai, Y., Shimada, T., Yasumori, K., Ibayashi, S. and Okada, Y. (2003) Reversible Posterior Leukoencephalopathy Syndrome in a Postpartum Woman without Eclampsia. Internal Medicine, 42, 1139-1143. http://dx.doi.org/10.2169/internalmedicine.42.1139

[11] Razmara, A., Bakhadirov, K., Batra, A. and Feske, S. (2014) Cerebrovascular Complications of Pregnancy and the 
Postpartum Period. Current Cardiology Reports, 16, 532. http://dx.doi.org/10.1007/s11886-014-0532-1

[12] Rijal, J., Giri, S., Dawadi, S. and Dahal, K. (2014) Posterior Reversible Encephalopathy Syndrome (PRES) in a Patient with Late Postpartum Eclampsia. BMJ Case Reports, 2014, bcr2013203162. http://dx.doi.org/10.1136/bcr-2013-203162

[13] Peng, W., Nakaii, M., Matsushima, T. and Asakura, H. (2008) Atypical Case of Reversible Posterior Leucoencephalopathy Syndrome Associated with Puerperal HELLP Syndrome. Archives of Gynecology and Obstetrics, 278, $269-271$. http://dx.doi.org/10.1007/s00404-008-0578-7

[14] Negro, A., Zuccoli, G., Regolisti, G., Mastrangeli, S. and Rossi, E. (2005) Reversible Posterior Leukoencephalopathy Associated with Postpartum HELLP Syndrome. European Journal of Internal Medicine, 16, 291-293. http://dx.doi.org/10.1016/j.ejim.2004.11.010

[15] Oyinloye, O., Adesiyun, O., Atobatele, M. and Fawole, A. (2014) Posterior REVERSIBLE Encephalopathy Syndrome in a Adult Female. Annals of African Medicine, 13, 138-141. http://dx.doi.org/10.4103/1596-3519.134422

[16] Vijayalakshmi, B., Sethna, F., Manford, M. and Lees, C. (2010) Posterior Reversible Encephalopathy Syndrome in a Patient with HELLP Syndrome Complicating a Triploid Pregnancy. Journal of Maternal-Fetal and Neonatal Medicine, 23, 938-943. http://dx.doi.org/10.3109/14767050903317690

[17] Okada, T., Kanagaki, M., Yamamoto, A., Fushimi, Y. and Togashi, K. (2013) Magnetic Resonance Imaging of Vascular Encephalopathy Related to Pregnancy. Neurologia Medico-Chirugica (Tokyo), 53, 520-525. http://dx.doi.org/10.2176/nmc.53.520

[18] Paul, B., Juneja, S., Paul, G. and Gupta, S. (2013) Spectrum of Neurological Complications in HELLP Syndrome. Neurology India, 61, 467-471. http://dx.doi.org/10.4103/0028-3886.121909

[19] Maggi, G., Lombana, V., Marcos, E., Ruiz Huerta, A., Arévalo, E. and Rodríguez, F. (2013) Posterior Leukoencephalopathy Syndrome: Postpartum Focal Neurologic Deficits: A Report of Three Cases and Review of the Literature. Saudi Journal of Anaesthesiology, 7, 205-209. http://dx.doi.org/10.4103/1658-354X.114056

[20] Duley, L., Henderson-Smart, D. and Meher, S. (2003) Drugs for Treatment of Very High Blood Pressure during Pregnancy. Cochrane Database Systemic Reviews, 3, Article ID: CD001449.

[21] Hutcheon, J., Lisonkova, S. and Joseph, K. (2011) Epidemiology of Pre-Eclampsia and the Other Hypertensive Disorders of Pregnancy. Best Practice \& Research Clinical Obstetrics \& Gynaecology, 25, 391-403. http://dx.doi.org/10.1016/j.bpobgyn.2011.01.006

[22] Altman, D., Carroli, G., Duley, L., Farrell, B., Moodley, J., Neilson, J., Smith, D. and Group, M.T.C. (2002) Do Women with Preeclampsia, and Their Babies, Benefit from Magnesium Sulphate? The Magpie Trial: A Randomised Placebo-Controlled Trial. Lancet, 359, 1877-1879. http://dx.doi.org/10.1016/S0140-6736(02)08778-0 